\title{
ORAL MYOFUNCTIONAL AND ELECTROMYOGRAPHIC EVALUATION OF THE ANTERIOR SUPRAHYOID MUSCLES AND TONGUE THRUST IN PATIENTS WITH CLASS II/1 MALOCCLUSION SUBMITTED TO FIRST PREMOLAR EXTRACTION
}

\author{
Denize Ramirez de SOUZA ${ }^{1}$, Tatiana Adamov SEMEGHINI², Lucio Benedito KRÖLL ${ }^{3}$, Fausto BERZIN ${ }^{4}$
}

1- Speech-Language Pathologist, M.Sci. in Physiology of the Exercise by São Paulo Federal University - UNIFESP - São Paulo - Brazil. 2- DDS, PhD in Bucco-Dental Biology, Professor, Master's degree Program in Physiological Sciences, University of Western São Paulo State, Presidente Prudente, São Paulo, Brazil.

3- Statistician, PhD in Statistics, Professor, Master's degree Program in Physiological Sciences, University of Western São Paulo State, Presidente Prudente, São Paulo, Brazil.

4- DDS, PhD in Anatomy, Chair Professor, State University of Campinas, Campinas, São Paulo, Brazil.

Corresponding address: Denize Ramirez de Souza - Av: Washington Luis 2536 sl 401 - Cep.: 19023-550 - Presidente Prudente, SP, Brazil phone/fax: +55 1832212144 - e-mail: denize@prudenet.com.br

Received: December 02, 2005 - Modification: October 19, 2006 - Accepted: January 05, 2007

\begin{abstract}
bjective: The aim of this study was to assess the existence of myofunctional alterations before and after first premolar extraction in Class II/1 malocclusion patients that could endanger the long-term dental arch stability. Materials and Methods: The study was performed by means of morphological, functional and electromyographic analyses in $17 \mathrm{Class}$ II/1 malocclusion patients (group T) and 17 Class I malocclusion patients (group C), both groups with 12-30-year age range (mean age: $20.93 \pm$ 4.94 years). Results: Data analyzed statistically by Student's t-test showed a significant decrease in the maxillary and mandibular dental arch perimeters after orthodontic treatment $(p<0.05)$. The Kruskal-Wallis test analyzed data from tongue posture at rest and during swallowing, not showing significant differences after treatment (groups $\mathrm{Tb}$ and $\mathrm{Ta})(\mathrm{p}>0.05)$. However, group $\mathrm{T}$ differed significantly from group $\mathrm{C}(\mathrm{p}<0.05)$. The electromyographic data showed that the anterior right and left suprahyoid muscles acted synergistically in both groups, while having a lower myoelectric activity in group $\mathrm{T}$ during swallowing. Conclusions: Myofunctional alterations observed after the orthodontic treatment in Class II/1 malocclusion seemed to jeopardize the long-term orthodontic stability, making recurrence possible. Further research should be conducted to compare electromyographic data before and after orthodontic treatment in order to corroborate the results of the present investigation.
\end{abstract}

Uniterms: Neck muscles; Tongue; Electromyography; Oral myofunctional evaluation; Malocclusion; Tooth extractions.

\section{INTRODUCTION}

The pressures exerted by the orofacial muscles were first mentioned as etiologic factors of malocclusions early back in the 19th century ${ }^{8}$. This clearly shows a long-term concern of researchers about muscle activity and functional alterations of the stomatognathic system ${ }^{26}$, which are interrelated with dental malposition ${ }^{2,4,14,17,20,23}$, especially in patients with Class II subdivision 1 (Class II/1) malocclusions.

Extraction of the first premolars is usually indicated for this type of malocclusion in order to solve the existing anteroposterior maxillomandibular discrepancy ${ }^{2}$. Anderson ${ }^{2}$ has reported that there is a possibility of recurrence in these cases due to the decrease of dental arch perimeter after extraction of the first premolars and closure of their spaces. Many hypotheses have been raised to explain the causes of recurrence and reduction of the dental arch perimeter, among which is depriving the tongue of its essential space ${ }^{14}$.

The pressure on the premolar region during swallowing in Class II/1 patients is twice stronger than in individuals with normal dental occlusion ${ }^{19}$. This is region acts as redistributor of strength and can be strongly affected by differences between size and shape and/or skeletal unbalances ${ }^{27}$.

It is important to emphasize that the strength generated by an inadequate tongue posture at rest causes more damage to the dental arches than during swallowing because, despite being low, they are constant ${ }^{30}$. As a result of the tongue 
interposition during swallowing and its abnormal pressure on the oral cavity, the anterior/posterior teeth can be protruded upward and forward, thus increasing overjet ${ }^{4}$.

The functions executed by the stomatognathic system require the effective participation of the suprahyoid muscles, mainly during swallowing, allowing the contraction of the mouth floor and forcing the tongue against the palate. Therefore, the electromyographic analysis of this function is of great value because differences in muscle activity during function can be identified and correlated to the occlusion.

There is a high level of activity in the milohyoid muscle during functions of the stomatognathic system, such as swallowing and suction, specially during the beginning of the swallowing oral phase in which the muscle produces a strong contraction strength ${ }^{3,18}$. Regarding the straw suction, Douglas ${ }^{12}$ compared the tongue movements with diving. The tongue is forced against the palate and makes the sealing. Then, its retraction movements trigger the contraction of the whole milohyoid muscle, which cooperates with the movements ${ }^{12}$.

The variability of swallowing reflects the plasticity of this function and is necessary to adjust to the physiologic changes and mechanical conditions. These adaptation patterns seem to be required for a new programming and control of the swallowing movements facing the mechanical obstruction ${ }^{25}$.

Therefore, the aim of this study was to assess, by means of morphological, functional and electromyographic analyses, the existence of myofunctional alterations before and after first premolar extraction in Class II/1 malocclusion patients that could endanger the long-term dental arch stability, comparing the results to those of a control group.

\section{MATERIALAND METHODS}

The research protocol was reviewed by the Ethics in Human Research Committee of the University of Western São Paulo State and the study design was approved (protocol no012/001).

Thirty-four volunteers of both genders, aged 13 to 30 years were selected and assigned to 2 groups $(n=17)$ : group $\mathrm{T}$ - Class II/1 malocclusion (verified by cephalometric analysis protocol) treated orthodontically with extraction of the mandibular and/or maxillary first premolars; and group C Class I malocclusion without tooth crowding (control).

This study was conducted in two stages:

First stage - a) Oral myofunctional evaluation, verified by visual inspection of tongue posture, during water swallowing $(20 \mathrm{~mL})$; b) Evaluation of tongue posture at rest, studied by teleradiographs with barium-sulphate contrast put on the dorsum of the tongue; c) Measurement in millimeters on plaster models using the Arch Measuring Instrument ("Amigo" - The Company) for analysis of the mandibular and maxillary dental arch perimeters. All of these situations were evaluated before (group $\mathrm{Tb}$ ) and after (group Ta) the orthodontic treatment during a 24-month period for each patient. All evaluations were done in two days, one before and one after orthodontic treatment. The first premolars were extracted during the course of the orthodontic therapy, according to the treatment plan. The pre-and post-orthodontic treatment data of the group $\mathrm{T}$ were compared to pre-and postorthodontic treatment data of the group $\mathrm{C}$ in the same day of data collection.

Second stage - b) Electromyographic evaluation of the anterior right and left suprahyoid muscles after completion of the orthodontic treatment in group Ta and group $\mathrm{C}$ patients (complementary study) was performed. Data was acquired in root medium square (RMS) and expressed as $\mu \mathrm{V}^{3}$.

The muscle electric potential was captured by a signalconditioning module (SCM) (1000-V2) (Lynx Electronics Technologies, São Paulo, SP, Brazil) to which passive electrodes were connected. The analogical signals were stored on the SCM and filtered with a range of cutting frequency from $20 \mathrm{~Hz}$ to $500 \mathrm{~Hz}^{1}$ through a butterworth analogical filter and 600 times final gain amplification. The system had analogto-digital (A/D) signal conversion plate of 12-bit resolution and support DMA (direct memory access) with $2000 \mathrm{~Hz}$ sampling frequency and software for data acquisition and storage (Lynx Electronics). Signal processing was performed with MATLAB 5.0 software to obtain the RMS data ${ }^{3}$.

The volunteers were oriented to comfortably keep their backs on the chair back, maintaining their feet parallel, touching the floor, and their heads positioned with the Frankfurt plan parallel to the floor. The volunteers had their skin cleaned with $70 \%$ alcoholic solution to avoid any interference that could decrease the impedance. For each studied muscle, a pair of electrodes was used with $1-\mathrm{cm}$ distance between their poles. They were placed following the longitudinal direction of the fibers ${ }^{10}$ and were connected to the fist anterior region of the volunteers. Electric potentials of the anterior right and left a suprahyoid muscles were recorded during 2 seconds per procedure.

Recording started after stabilization of the electromyographic signal, according to the following protocol: a) continuous water suction using a straw during recording; b) two-minute rest between records ${ }^{10}$; c) swallowing of $20 \mathrm{~mL}$ water after investigator's verbal command. These recordings were repeated 3 times. As reference muscle contraction, the electromyographic means obtained during dynamic activity were used. Data normalization was performed using the formula: rms values $(\mu \mathrm{V})$ during swallowing/ $\mathrm{RMS}$ values $(\mu \mathrm{V})$ during suction $\mathrm{x} 100^{24}$.

Data collected in the Stage 1 were analyzed statistically by Kruskal-Wallis test (groups Tb and Ta) and Student's ttest (group C). Data collected in the Stage 2 were analyzed statistically by ANOVA and Tukey-Kramer test, except for the cases with non-normal data distribution, which were analyzed by Kruskal-Wallis non-parametric test.

\section{RESULTS}

Oral myofunctional evaluation and visual inspection of tongue posture during water swallowing showed that $82.3 \%$ of patients in group $\mathrm{Tb}$ presented tongue thrust during swallowing, while $17.6 \%$ had normal posture during this 
function, that is the anterior third of the tongue touched the incisal papilla and the palate close to the palatal surface of the maxillary incisors, while the lips were kept sealed. In group Ta, $94.1 \%$ of the volunteers had tongue thrust and $5.8 \%$ had normal tongue posture. In group C, $100 \%$ of the subjects presented normal tongue posture during swallowing.

Comparing group $\mathrm{C}$ to groups $\mathrm{Tb}$ and $\mathrm{Ta}$, there were statistically significant differences in tongue posture during swallowing $(\mathrm{p}=0.05)$. However, no significant differences were observed between groups Tb and Ta $(\mathrm{p}>0.05)$ (Table 1$)$.

Regarding tongue posture at rest, $47.1 \%$ of group $\mathrm{Tb}$ subjects presented adequate tongue posture (outlining the palate) at rest while in $52.9 \%$ of the volunteers tongue posture was adapted to the dental arch (lower tip and higher dorsum). On the other hand, $29.5 \%$ of group Ta and $100 \%$ of group C had an adequate tongue posture at rest, whereas $70.5 \%$ of group Ta presented tongue thrust, which is considered an inadequate posture from a myofunctional standpoint. The usual tongue posture at rest before and after orthodontic treatment in group T had a statistically similar pattern $(\mathrm{p}>0.05)$, which, however, differed from that of group $\mathrm{C}(\mathrm{p}<0.05)$ (Table 2).

Comparison of the maxillary and mandibular dental arch perimeters of the three groups by the Student's t-test (Table 3 ) showed that, regarding the maxillary dental arch, group $C$ was similar to group $\mathrm{Tb}(\mathrm{p}>0.05)$ and both differed from group Ta, which had the shortest maxillary dental arch perimeters. Regarding the mandibular dental arch, group $C$ presented the largest perimeters and differed significantly from groups $\mathrm{Tb}$ and Ta, $(\mathrm{p}<0.05)$, which, however, did not differ to each other $(\mathrm{p}>0.05)$ (Table 3$)$.

The results of the electromyographic analysis of the anterior suprahyoid muscles during suction and swallowing for subjects in group $\mathrm{C}$ and group Ta are given on Table 4 . There were statistically significant differences between groups $\mathrm{C}$ and $\mathrm{Ta}$ for both sides (right and left) $(\mathrm{p}<0.05)$. However, no significant differences were observed between the anterior left and right suprahyoid muscles within the same group (either group C or group Ta) (Table 4).

\section{DISCUSSION}

The findings of the present study showed that more than eighty percent of the patients in group $\mathrm{Tb}$ presented tongue thrust during water swallowing (Table 1), which is in agreement with the results of previous studes ${ }^{4,9,13,26}$. Such observation can be related to the excessive overjet of Class II/1 malocclusion patients and seems to trigger the contraction of perioral muscles to promote the contact between the lips, contributing to tongue projection towards the incisors in order to seal the oral cavity. This mechanism maintains the negative intraoral pressure, which is important for food propulsion during the oral phase of swallowing ${ }^{12}$. On other hand, all volunteers in group $\mathrm{C}$ had normal lingual posture, which means that anterior the third of the tongue touched the incisal papilla and the palate close to the palatal surface of the maxillary incisors, while the lips remained sealed in Class I malocclusion ${ }^{12,26,30}$.

TABLE 1- Comparison of the groups regarding tongue posture during swallowing

\begin{tabular}{cl}
\hline Groups & Value-p \\
\hline Group C vs. Group Tb & $\mathrm{p}<0.001^{*}$ \\
Group C vs. Group Ta & $\mathrm{p}<0.001^{*}$ \\
Group Tb vs. Group Ta & $\mathrm{ns}$ \\
\hline
\end{tabular}

ns - Non significant. * Significant at $5 \%$ level (KruskalWallis test).

TABLE 2- Comparison of the groups regarding usual tongue posture at rest

\begin{tabular}{cl}
\hline \multicolumn{1}{c}{ Groups } & Value-p \\
\hline Group C vs. Group Tb & $\mathrm{p}<0.01^{*}$ \\
Group C vs. Group Ta & $\mathrm{p}<0.001^{*}$ \\
Group Tb vs. Group Ta & $\mathrm{ns}$ \\
\hline
\end{tabular}

ns - Non significant. * Significant at $5 \%$ level (KruskalWallis test).

TABLE 3- Comparison of the groups regarding the maxillary and mandibular dental arch perimeters (in $\mathrm{mm}$ )

Treatment

Means (mm) ( $\pm S D)$

$\begin{array}{ll}\text { Maxillary Arch Group C } & 138.1176 \pm 8.46 \mathrm{~A} \\ \text { Maxillary Arch Group Tb } & 133.5882 \pm 9.47 \mathrm{AB} \\ \text { Maxillary Arch Group Ta } & 125.9412 \pm 7.23 \mathrm{C} \\ \text { Mandibular Arch Group C } & 130.7647 \pm 8.15 \mathrm{D} \\ \text { Mandibular Arch Group Tb } & 124.5882 \pm 8.89 \mathrm{E} \\ \text { Mandibular Arch Group Ta } & 120.7059 \pm 6.61 \mathrm{E} \mathrm{F}\end{array}$

*Different letters indicate statistically significant difference at $5 \%$ (Student's t-test)

TABLE 4- Results of the electromyographic analysis during swallowing by suction of the anterior suprahyoid muscles for Groups C and Ta

Treatment

SHL Group C

SHR Group C

SHL Group Ta

SHR Group Ta

$\mathrm{SHL}=$ anterior left suprahyoid muscles, SHR - anterior right suprahyoid muscles; *Different letters indicate statistically significant difference at $5 \%$ 
The usual tongue posture at rest, as observed on teleradiographs with barium-sulphate contrast put on the dorsum of the tongue, was considered 'adapted' (i.e., lower tip and higher dorsum of tongue) in more than half the patients in group $\mathrm{Tb}$ (Table 2), which demonstrates an adjustment of the tongue to the shape of the dental arches ${ }^{4,6,9,26}$. It has been reported that this fact can be related to the discrepancy between the bone bases ${ }^{4,6,9,26}$.

Nevertheless, our results are not consistent with those of other authors, who focused on other lingual postures such as forwarding or interposition of tongue between the dental arches due to accentuated overjet ${ }^{15}$. In this study, the usual tongue posture at rest was considered adequate in $47.1 \%$ of group $\mathrm{Tb}$ and in all patients of group $\mathrm{C}$, who presented the dorsum of the tongue elevated outlining the palate, while the anterior third of the tongue remained on the palatal surface of the maxillary incisors, touching the lingual surface of the mandibular incisors ${ }^{6}$. Although this posture is a characteristic of Class I malocclusion (group C) ${ }^{6}$, it was not expected in Class II/1 malocclusion (group Tb). However, many factors might interfere with the usual tongue posture at rest, including other functional alterations such as ethnical and hereditary factors ${ }^{6}$. It was observed that about seventy percent of the patients in group Ta presented a lingual posture considered as adapted, while nearly thirty percent of the subjects kept the adequate posture at rest. Therefore, an increase in the number of patients with lingual posture considered as inadequate was observed at rest after the orthodontic treatment, allowing inferring that the usual tongue posture at rest became forwarded, being positioned between the incisors. Comparing the pre-and post-orthodontic treatment tongue posture at rest, no significant changes were observed (Table 2) ${ }^{26}$. However, significant differences were found between the usual tongue posture at rest in group $\mathrm{C}$ compared groups $\mathrm{Tb}$ and $\mathrm{Ta}$, suggesting that first premolar extraction, which is indicated for Class II/1 correction, may not promote an adequate tongue posture in some cases, but instead might lead the tongue to a forwarded posture, jeopardizing the dental arch stability after the treatment ${ }^{23}$.

Significant difference was found in the dental arch perimeters after completion of the orthodontic treatment (Table 3). In this study, the maxillary dental arch perimeters of the patients in group $\mathrm{C}$ were similar to those in group $\mathrm{Tb}$. This situation can be explained due to the fact that Class II/1 malocclusion patients may present a greater increasing tendency of the face lower third ${ }^{29}$ and disharmony in the apical bone bases, in an anteroposterior direction ${ }^{4}$. This interferes with the relationship between the maxillomandibular complex and the skull base ${ }^{22}$, thus becoming different from Class I. On the other hand, Class I subjects usually have a U-shaped maxillary arch, while dental arch geometry in Class II/1 malocclusion can be similar to the ' $\mathrm{V}$ ' letter. The differences in arch shapes however, do not modify their perimeter because the number of teeth in both cases is similar and normally there is no tooth crowding in the maxillary arch. This hypothesis seems to support the statistically similar values of the maxillary arch perimeters between the groups.

On the other hand, the mandibular dental arch perimeter of group $\mathrm{Tb}$, was statistically significant smaller than that of group
$\mathrm{C}$ (Table 3). This result can be attributed to the fact that most group $\mathrm{Tb}$ patients presented tooth crowding and, in similar cases, the lower lip can incline the anterior teeth towards lingual direction, which can decrease the arch perimeter; however, these conditions were not shown in Class I subjects (C group).

Comparing the maxillary and mandibular dental arch perimeters of groups $\mathrm{C}$ and $\mathrm{Ta}$, and the maxillary dental arch perimeters of groups $\mathrm{Tb}$ and $\mathrm{Ta}$, statistically significant differences were observed (Table 3 ). The treated groups showed a decrease in dental arch perimeters due to tooth retraction for correction of Class II/1 malocclusion ${ }^{2,5,7}$. The mandibular dental arch perimeters of groups $\mathrm{Tb}$ and $\mathrm{Ta}$ did not show significant differences (Table 3) because the volunteers in group $\mathrm{T}$ did not have their mandibular premolars extracted during the orthodontic therapy, according of treatment planning.

The electromyographic analysis (Table 4) of groups C and Ta demonstrated that the suprahyoid muscles act synergistically (anterior left and right sides) during swallowing ${ }^{11}$. However, when the RMS normalized values of these muscles were compared, statistically significant differences were observed between the groups. The anterior left and right suprahyoid muscles of group $\mathrm{C}$ patients showed greater myoelectric activation compared to group Ta patients $\mathrm{s}^{3,18,21,25}$. This fact suggests that, although the suprahyoid muscles presented perfect coordination in both groups, group $\mathrm{C}$ had greater myoelectric activity. This suggests that in volunteers with normal occlusion and swallowing, the jaw is stabilized at the moment of swallowing due to the contraction of the jaw elevator muscles and the anterior suprahyoid muscles, which elevate the hyoid bone to its highest position, and consequently to the anterior third of the tongue that reaches the hard palate ${ }^{12}$. This massive elevation of the tongue shortens the floor of the mouth which, together with hyoid bone elevation promotes a strong recruitment of the anterior suprahyoid muscles during swallowing ${ }^{3,12}$. Nevertheless, in individuals with tongue thrust (i.e., those with muscle unbalance, as group Ta patients), the jaw elevator muscles do not contract and the anterior third of the tongue do not rise massively against the palate. It places itself between the dental arches not allowing contraction of the elevator muscles and causing a strong recruitment of the suprahyoid muscles because mandibular stabilization seems to be important for the suprahyoid muscles to act, elevating the suprahyoid muscles during swallowing ${ }^{12}$.

The findings of the present study show that the tongue posture was forwarded both at rest and during swallowing. These results demonstrate that the long-term stability after completion of the orthodontic treatment, aimed by all orthodontists ${ }^{2,8}$, can be jeopardized if myofunctional alterations, when present, are not treated after removal of the orthodontic appliance due to possibility of recurrence ${ }^{2}$. Some authors refer to the modiolus region, situated above the premolars, as a force redistributor ${ }^{19,28}$ and report that tongue force in this region is more intense than that force of the perioral muscles ${ }^{18}$.

\section{CONCLUSIONS}

Based on the outcomes of the present study, it may be 
concluded that the orthodontic treatment in Class II/1 malocclusion patients decreased dental arch perimeter. The anterior right and left suprahyoid muscles were shown to act synergistically in both treated and control groups; however, the patients in the treated group presented a lower myoelectric activity during swallowing. The myofunctional alterations observed after the orthodontic treatment in Class II/1 malocclusion patients seem to jeopardize the long-term orthodontic stability, making recurrence possible. Thus, the evaluation and myofunctional treatment supporting the orthodontic treatment can be of great importance for restoring the myofunctional balance of the stomatognathic system, avoiding recurrence. Further research should be conducted to compare electromyographic data before and after orthodontic treatment in order to corroborate the results of the present investigation.

\section{REFERENCES}

1- Acierno SP, Baratta RV, Solomonow M. A practical guide to electromyography for biomechanics. New Orleans: Louisiana State University; 1995

2- Anderson BD. Multiple extraction patterns in severe discrepancy cases. Angle Orthod. 1975;45(4):291-303.

3- Basmajian JV, De Luca CJ. Muscle alive: their function revealed by eletromyography. 5th ed. Baltimore: Williams and Wilkins; 1985.

4- Bianchini EMG. A cefalometria nas alterações miofuncionais orais: diagnóstico e tratamento fonoaudiológico. São Paulo: Prófono; 1995.

5- Bishara SE, Cummins DM, Jakobsen JR. Treatment and posttreatment changes in patients with Class II/ 1 , malocclusion after extraction and nonextraction treatment. Am J Orthod Dentofacial Orthop. 1997;111(1):18-27.

6- Cardoso RK, Giellow T, Mattos MC. Posicionamento habitual de língua nos padrões faciais ântero-posteriores. In: Marchesan IQ, coordenador. Tópicos de fonoaudiologia. São Paulo: Lovise; 1998.

7- Carvalho PEG, Henriques JFC, Pinzan A, Freitas MR, Janson GRP A influência do padrão de crescimento facial anterior na correção da má oclusão de classe II, 1 . $^{\mathrm{a}}$ divisão, realizada com aparelho fixo, extração dos primeiros pré-molares e ancoragem extrabucal cervical. Ortodontia. 2000;33(3):8-24.

8- Case CS. The question of extraction in orthodontia Trans NDA 1911 [reprinted]. Am J Orthod. 1964;50(1):658-91

9- Cleal JF. Deglutition a study of form and function. Am J Orthod. 1965;51(1):566-94

10- De Luca CJ. The use of surface eletromyography in biomechanics. J Appl Biomech. 1997;13(1):135-63

11 - Doty RW, Bosma J. An electromyographic analysis of reflex deglutition. J Neurophysiol. 1956;19(1):44-60

12 - Douglas CR. Tratado de fisiologia aplicada a fonoaudiologia. São Paulo: Robe; 2002.

13- Fink FS. The tongue, the lingometer, and the role of accommodation in occlusion. Angle Orthod. 1986;56(3):225-33.

14- Hanson ML, Barret RH. Fundamentos de miologia orofacial. Rio de Janeiro: Enelivros; 1995.
15- Hanson ML, Cohen MS. Effects of form and function on swallowing and the developing dentition. Am $\mathrm{J}$ Orthod. 1973;64(1):63-82.

16- Kydd WL, Toda JM. Tongue pressures exerted on the hard palate during swallowing. J Am Dent Assoc. 1962;65(6):319-30.

17- Lear CSC, Moorees CFA. Buccolingual muscle force and dental arch form. Am J Orthod. 1969;56(4):379-93.

18- Lehr RP, Banton PL, Biggs NL. An electromyographic study of the mylohyoid muscle. Anat Rec. 1971;169(4):651-60.

19- Lightoller GHS. Facial muscles. The modiolus and muscles surrounding the rima oris with some remarks about panniculus adiposus. J Anat. 1925;60(1):1-85.

20- Lowe AA, Takada K. Associations between anterior temporal, masseter and orbiculares oris muscle activity and craniofacial morphology in children. Am J Orthod. 1984;86(4):319-30.

21- Murray KA, Larson CR, Logemann JA. Eletromyographic response of the labial muscles during normal liquid swallows using a spoon, a straw and a cup. Dysphagia. 1998;13(1):160-6.

22- Pfeiffer JP, Grobét D. A philosophy of combined orthopedicorthodontic. Am J Orthod. 1982;81(3):185-201.

23- Prabhu \& MunshI NT, Munshi AK. Ultrasonographic observation of the circumoral musculature: an in-vivo study. The J Clin Pediatr Dent. 1995;19(3):195-203.

24- Soderberg GL, Knutson LM. A guide of use and interpretation of knesiologic electromyographic date. Phys Ther. 2000;80(5):48598.

25- Spiro J, Rendell JK, Gay T. Activation and coordination patterns of the suprahyoid muscles during swallowing. Laryngoscope. 1994;106(1):1376-82

26- Subtelny JD. Malocclusions, orthodontic corrections and orofacial muscle adaptation. Angle Orthod. 1970;3(1):170-201.

27- Tomé MC, Marchiori SC. Estudo eletromiográfico dos músculos orbiculares superior e inferior da boca em crianças respiradoras nasais e bucais durante o repouso com e sem contato labial. J Bras Ortodon Ortop Facial. 1998;3(15):59-66.

28- Tomé MC, Marchiori SC. Análise eletromiográfica dos músculos orbiculares superior e inferior da boca em crianças respiradores nasais e bucais durante a deglutição e o sopro. Rev Soc Bras Fonoaudiol. 1998;4(1):16-21.

29- Vale DMV do, Martins DR. Avaliação cefalométrica das estruturas dento-esqueléticas em jovens portadores de Classe II, 1. ${ }^{a}$ Divisão, brasileiros, leucodermas e de origem mediterrânea. Ortodontia. 1987;20(1-2):5-17.

30 - Van Der Linden FPGM. Ortodontia: desenvolvimento da dentição. São Paulo: Quintessence; 1986. 